\title{
A Pandemia Covid-19 Como Um Inimigo Invisível E Silencioso: O Direito À Saúde Em Tempos De Sobrevivência
}

\author{
Janaína Machado Sturza* \\ Universidade Regional do Noroeste do Estado do Rio Grande do Sul. Programa de Pós- \\ Graduação em Direitos Humanos, Ijuí-RS, Brasil.
}

(iD) http://orcid.org/o0oo-0001-9290-1380

\begin{abstract}
Evandro Luís Sippert**
Universidade Regional do Noroeste do Estado do Rio Grande do Sul. Programa de Pós-

Graduação em Direitos Humanos, Ijuí-RS, Brasil.

(iD) https://orcid.org/000o-00o1-6810-3266
\end{abstract}

Resumo: O direito à saúde está relacionado a uma garantia imprescindível ao pleno desenvolvimento e satisfação da qualidade de vida das pessoas, pois ao centro de tudo deve estar o respeito pelo homem, por sua dignidade e por seus direitos inalienáveis, essenciais à sua sobrevivência em um mundo no qual os riscos se mostram globalizados, invisíveis e silenciosos. Nesse sentido, o estudo ora proposto tem por objetivo analisar as implicações da disseminação da pandemia do vírus Covid-19 no direito à saúde, em um contexto de crise global em caráter sanitário e humanitário. Este artigo constitui-se em uma revisão bibliográfica, baseada no método dedutivo e utilizando-se, como alternativa de analise, da metateoria do Direito Fraterno. Por fim, verificou-se que esta pandemia nos apresentou a necessidade da ruptura de paradigmas, a partir da ressignificação da sociedade, especialmente sob o olhar do direito ao acesso à saúde como forma de sobrevivência.

Palavras-chaves: Crise sanitária. Direito à saúde. Pandemia. Sobrevivência.

\footnotetext{
* Doutora em Direito pela Universidade de Roma Tre/Itália. Professora na UNIJUI, na graduação e no Programa de pós-graduação em Direito. E-mail: janasturza@hotmail.com

** Doutorando e Mestre em Direito pela Universidade Regional do Noroeste do Estado do Rio Grande do Sul - UNIJUí. E-mail: evandro.sippert@gmail.com
}

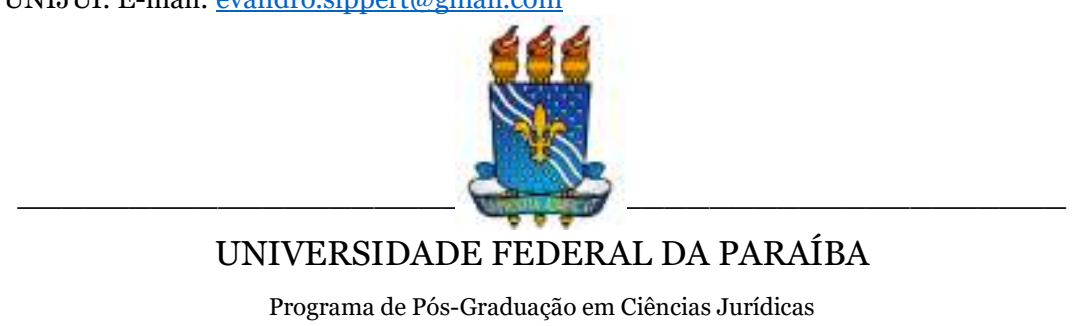

DOI: https://doi.org/10.22478/ufpb.1678-2593.2020v19n42.54163 


\title{
A Pandemia Covid-19 Como Um Inimigo Invisível E Silencioso: O Direito À Saúde Em Tempos De Sobrevivência
}

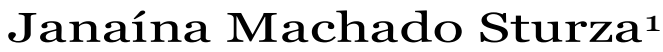

Evandro Luís Sippert

\section{INTRODUÇÃO}

Na sociedade contemporânea, a saúde pode ser considerada como um bem comum ${ }^{2}$ a todos, como um direito fundamental social 3 necessário à manutenção da vida. Entretanto, o reconhecimento de sua eficácia é um forte argumento colocado em discussão nos dias atuais, principalmente em relação aos "direitos sociais e as externalidades que não podem ser internalizadas na avaliação da saúde enquanto bem econômico (DALLARI, 1987, p. 15)”.

\footnotetext{
${ }^{1}$ O presente trabalho foi realizado com apoio da FAPERGS - PqG Edital 05/2019.

2 Para a definição de bens comuns, cita-se Melo (1978, p. 12), para quem "BemComum: Diz-se dos fatores propiciados pelo Estado com vistas ao bem-estar coletivo, formando o patrimônio social e configurando o objetivo máximo da Nação. Valor organizador da coletividade que caracteriza seu estado ou sua condição. A ordem social justa. O mesmo que interesse público". Oportunas também são as palavras de Silva (1990, p. 304-305), no sentido de que "bens comuns pode ser tido em duas acepções perfeitamente distintas. Pode ser entendido no sentido de bens inapropriáveis, isto é, que não são suscetíveis de um apoderamento por parte da pessoa, a fim de que os particularize em proveito ou utilidade própria. Serão os bens comuns a todos (res omnium communes) ou communia, omnium, na linguagem romana. Mas, para os distinguir da outra espécie, dos bens comuns apropriados, também se dizem, no primeiro sentido, bens de uso público, para indicar que são bens de uso de todos os habitantes de um lugar. São bens que se dizem públicos, justamente, porque, mesmo quando apreensíveis, não estão no comércio, não podendo, assim, ser objeto de apropriação ou ocupação pelo particular. No segundo sentido, bens comuns designam os bens que são possuídos em comunhão: tem dois ou mais titulares, pertencem a todos eles em comunidade".

3 Art. $6^{\circ}$ São direitos sociais a educação, a saúde, o trabalho, a moradia, o lazer, a segurança, a previdência social, a proteção à maternidade e à infância, a assistência aos desamparados, na forma desta Constituição.
} 
É possível afirmar-se que a saúde - ou em outros termos, o direito à saúde, representa uma importante prerrogativa à vida do homem, ao mesmo tempo em que, nas muitas situações da vida diária, acaba sendo ameaçada. A saúde é primordial ao ser humano que, na sua individualidade - ou mesmo em situações de vivências coletivas, necessita de uma garantia a este direito essencial à sua sobrevivência, uma vez que em sociedades "ditas democráticas", as dificuldades residem em permitir a manutenção da saúde em um mundo no qual os riscos também são globalizados e, muitas vezes invisíveis e silenciosos, tal qual a pandemia denominada de COVID-19.

Nesse contexto, percebe-se que esta pandemia, reconhecida como tal no dia 11 de março de 2020 pela Organização Mundial da Saúde (OMS), atingiu bruscamente a saúde e, por consequência, a vida de milhares de pessoas por todo o mundo.

Assim, pois, analisar as implicações no direito à saúde, em virtude da disseminação do Covid-19, em um contexto de crise global em caráter sanitário e humanitário, apresenta-se como objetivo central deste artigo. Nesta perspectiva, o estudo ora proposto constitui-se em uma revisão bibliográfica, baseada no método dedutivo e utilizando-se, como alternativa de analise, da metateoria do direito fraterno, defendida e idealizada pelo prof. italiano Eligio Resta. Esta alternativa de analise desvela-se a partir das consequências desencadeadas por um inimigo invisível e silencioso - o vírus Covid19, que está impondo de forma implacável uma necessária ressignificação da vida e, quiçá, da humanidade.

Diante disso, tornam-se essenciais algumas reflexões envoltas no campo da saúde, emergindo então os problemas que norteiam esse artigo: Historicamente, dispor de uma boa saúde sempre foram preocupações do homem e, neste sentido, em que medida se torna imprescindível o enfrentamento às dificuldades intrínsecas a saúde em cada momento histórico, principalmente aquelas relacionadas a sobrevivência? Uma vez que as doenças sempre estiveram presentes no caminho da humanidade e são oriundas dos mais diversos fatores, 
estaria a pandemia produzindo consequências substanciais e grandes repercussões de ordem social e econômica, levando em consideração que a propagação do Covid-19 potencializou os problemas, fazendo ingerência no sistema do direito e também no sistema de saúde? Por fim, é oportuno repensar o contexto no qual está inserido o direito à saúde junto à sociedade, por meio da metateoria do Direito Fraterno? Tais problemas serão respondidos ao longo do artigo, a partir dos fundamentos apresentados no decorrer dos seus capítulos.

É certo que tais indagações nos remetem a muitas dúvidas e incertezas. Este momento é realmente uma vivência atípica em tempos contemporâneos. Todavia, problemas como epidemias, doenças contagiosas dentre outros, sempre marcaram rupturas significativas na sociedade, sendo que também foram oportunidade para a sociedade poder se reinventar e se ressiginificar.

Mesmo com a positivação dos direitos e garantias fundamentais, dentre os quais se destaca o acesso à saúde, ainda com todo o avanço da ciência e da tecnologia em todos os níveis da vida, o surgimento de uma nova pandemia mundial que de forma avassaladora se proliferou por todo o mundo, mostra o quanto as pessoas continuam vulneráveis, principalmente as mais pobres, alguns grupos de risco e invariavelmente todas as pessoas, pois a falta de saúde afeta toda a ordem mundial, social e econômica.

Portanto, mais do que nunca se faz necessário e premente um direito que inclui, fundado num pacto entre irmãos, no qual o outro precisa ser visto como sendo parte do EU, pois a ideia do outro como irmão não suporta delimitações territoriais, nem outras delimitações e, desta forma, desvela-se de forma insofismável repensar o acesso ao direito à saúde, especialmente sob o olhar da metateoria do direito fraterno. 
A Pandemia Covid-19 Como Um Inimigo Invisível E Silencioso: 0 Direito À Saúde...

\section{AS DOENÇAS NO CAMINHO DA HUMANIDADE: REFLEXÕES E DELINEAMENTOS HISTÓRICOS- JURÍDICOS}

Em um mundo cada vez mais cosmopolita, que está passando por uma crise sanitária e humanitária, em virtude da pandemia do Covid-19, que pode(rá) ser considerada uma das mais graves crises, se faz necessário entender a dinâmica universalista das relações econômicas, sociais, políticas e históricas. Assim, em virtude desta conjuntura, a ruptura de paradigmas e a ressignificação de valores, serão significativas e inevitáveis, necessitando à sociedade, ao direito e à saúde, serem repensadas.

Nesse contexto, surge a necessidade premente de um direito que inclui a todos, fundado num pacto entre irmãos, tal qual nos coloca Eligio Resta (2004). Assim sendo, desvela-se de forma insofismável, a utilização da metateoria do direito fraterno, sobretudo repensando o direito à saúde em tempos de crise. Pois, apesar dos avanços tecnológicos e científicos do nosso tempo, a falta de saúde afeta toda a ordem mundial, social e econômica - e, mais uma vez, a saúde reafirma-se como um direito humano fundamental a todos.

Historicamente, ser saudável e dispor de uma boa saúde sempre foram preocupações constantes do homem. Para conseguir sobreviver, foi imprescindível que o homem, em cada momento histórico, estivesse em harmonia com o ambiente em que estava e conseguisse, desta forma, se adaptar e romper as barreiras naturais. "Em cada época histórica, os modos de viver dominantes (trabalho, consumo, lazer, convivência) e de antecipar ou adiar a morte, são relativamente rígidos e parecem decorrer de regras escritas na pedra da natureza humana. É verdade que eles se vão alterando paulatinamente, mas as mudanças passam [...] (SANTOS, 2020, p. 6).

Desta forma, a saúde da pessoa, condição fundamental para viver, está intimamente ligada com o ambiente em que ela vive e suas formas de vida, as condições do seu habitat, seus hábitos e todo o 
contexto que pode de alguma forma exercer ou ter influência na sua saúde e no seu bem-estar. Sem saúde o indivíduo não fica bem e, por conseguinte, nada fica bem. Quando se está com dor, e pode ser uma dor tanto física quanto emocional, o ser humano, muitas vezes, perde a sua própria razão de viver e a vida deixa de fazer sentido (SIPPERT, 2017). Alguns diagnósticos de doenças, mesmo com todo o desenvolvimento tecnológico disponível e avanço da medicina, pode ser a decretação do fim da vida, como no caso do Covid-19, para alguns grupos de risco.

Por conseguinte, ao longo da história humana, os grandes problemas de saúde que os homens enfrentaram estiveram relacionados com a natureza da vida em comunidade e todas as suas nuances, tais como o controle de doenças transmissíveis, o controle e a melhoria do ambiente físico (saneamento), a provisão de água e comida puras, a assistência médica e o alívio da incapacidade, entre outros. Pois, "quando o surto ocorre, a vulnerabilidade aumenta, porque estão mais expostos à propagação do vírus e se encontram onde os cuidados de saúde nunca chegam: favelas e periferias pobres da cidade, aldeias remotas, campos de internamento de refugiados, prisões, etc" (SANTOS, 2020, p. 26).

Assim, pois, em determinados momentos históricos, ocorreu o surgimento de doenças, principalmente as doenças contagiosas e transmissíveis, marcando profundamente a sociedade naquele momento de sua história, inclusive contribuindo para rupturas significativas. Na Idade Média4, duas epidemias marcaram o começo e o caos deste período: a peste de Justiniano (543) e a peste negra (1348)5. Entre essas duas datas, maiores ou menores surtos de doenças visitaram e arruinaram a Europa e o litoral mediterrâneo: lepra, peste bubônica, varíola, difteria, sarampo, influenza, ergotismo,

\footnotetext{
4 A desintegração do mundo greco-romano a partir do seu interior e sob o impacto das invasões bárbaras levou ao declínio da cultura urbana e à decadência da organização e da prática da Saúde Pública (CURY, 2005, p. 33).

5 [...] A Peste Negra na Europa, que dizimou cerca de 25 a 30 milhões de pessoas. Não deixa de ser curioso observar que a Peste Negra teve origem nas Cruzadas católicas, trazida que foi da Ásia ao seio do Velho Continente pelos "mártires" cristãos (SCHWARTZ, 2004, p. 46 - 47).
} 
tuberculose, escabiose, erisipela, antraz, tracoma, malária e a mania dançante (CURY, 2005, p. 33).

\begin{abstract}
Epidemias matavam milhões de pessoas bem antes da atual era da globalização. No século XIV, não havia aviões nem cruzeiros, e no entanto a peste negra disseminou-se da Ásia Oriental à Europa Ocidental em pouco mais de uma década. Matou entre 75 milhões e 200 milhões de pessoas - mais de um quarto da população da Eurásia. Na Inglaterra, quatro em cada dez pessoas morreram. A cidade de Florença perdeu 50 mil de seus 100 mil habitantes.

Em março de 1520, um único hospedeiro da varíola Francisco de Eguía - desembarcou no México. Na época, a América Central não tinha trens, ônibus, nem mesmo jumentos. No entanto, por volta de dezembro uma epidemia de varíola já devastava a América Central inteira, matando, de acordo com algumas estimativas, quase um terço de sua população (HARARI, 2020, p. 4).
\end{abstract}

Em que pese à visão eurocêntrica para determinar os períodos históricos, é certo que com a era moderna ocorreu também a colonialidade, e com esta a disseminação destas mazelas a grande maioria dos povos colonizados. Essa visão eurocêntrica, imposta de cima para baixo, aliado ao discurso da dominação, da imposição da cultura hegemônica em cima do conquistado, trouxe prejuízos inimagináveis para estas culturas, principalmente em termos de saúde, pois não raro eram povos que viviam isolados, sem contato com determinados tipos de doenças.

Porém, foi com as Declarações de Direitos, tanto a americana, quanto a francesa, que foram garantidos os direitos inatos e invioláveis, tais como a vida, a liberdade e a propriedade. Na lição de Bedin (2002), temos que a Declaração da Virgínia (1776) e a Declaração de Direitos do Homem e do Cidadão (1789) são os dois primeiros grandes indicadores de “[...] uma profunda mutação histórica: a emergência de um novo modelo de sociedade - modelo individualista - ou uma nova perspectiva de análise das relações políticas - perspectiva ex parte Popul”'(BEDIN, 2002, p. 38).

Foi neste contexto, que surgiu o direito individual, no qual se afirmava que os homens por natureza são titulares de um conjunto de direitos inalienáveis. Neste sentido, Norberto Bobbio leciona que os 
direitos do homem, em que pese serem direitos fundamentais, [...] "são direitos históricos, ou seja, nascidos em certas circunstâncias, caracterizados por lutas em defesas de novas liberdades contra velhos poderes, nascidos de modo gradual, nem todos de uma vez e nem de uma vez por todas" (BOBBIO, 1992, p. 5).

Já para Ferrajoli (2011, p. 107) "os direitos fundamentais são sempre leis dos mais fracos contra a lei dos mais fortes, esses valem, como direitos do indivíduo, para proteger as pessoas também - e acima de tudo - contra as suas culturas [...]”. Os direitos fundamentais são direitos e garantias do indivíduo em face do Estado, e que foram positivados tanto na Declaração Francesa, embasados nos ideais de igualdade, liberdade e fraternidade. Para Eligio Resta apud Sturza e Martini (2019), a fraternidade referida na revolução iluminista continua inédita e não resolvida em relação à igualdade e à liberdade.

Assim, a partir deste contexto histórico iluminista, também começa a ser desenvolvido o conceito de saúde pública, o qual se alinha com o reconhecimento dos direitos econômicos, sociais e culturais. Somente no século XIX que começou, segundo Roberts (2001), ainda que de forma frágil, a ser a era da conquista de vitórias sobre as doenças, por meio da aplicação consciente do conhecimento científico. Assim, o processo se iniciou quando os europeus perceberam que "[...] navios e marinheiros - embora não soubessem como - de certa forma traziam doenças e começaram aos poucos a implementar a quarentena nos portos" (Roberts, 2001, p. 539), pois como destaca Roberts (2001), outras doenças causavam danos como, por exemplo, os surtos de tifo, varíola, disenteria e cólera, os quais ocorreram repetidas vezes por muitas décadas e que foram piores em cidades metrópoles novas e de crescimento rápido.

Em 1918, uma cepa de gripe particularmente virulenta conseguiu se propagar em alguns meses pelos cantos mais remotos do planeta. Infectou meio bilhão de indivíduos mais de um quarto da espécie humana. Estima-se que a gripe tenha matado $5 \%$ da população da Índia. No Taiti, 14\% dos ilhéus morreram. Em Samoa, 20\%. Ao todo, a pandemia matou dezenas de milhões de pessoas chegando talvez a 100 milhões - em menos de um ano. Foi 
mais do que se matou em quatro anos de batalhas brutais na Primeira Guerra Mundial (HARARI, 2020, p. 4).

Não obstante, as epidemias e os surtos de doenças foram uma constante na história da humanidade, são inúmeros exemplos, inclusive recentes, como o $H_{1} N 1$, gripe suína, entre outros, que sempre assolam a humanidade de forma implacável, trazendo como consequências milhares de mortes. Porém, a incidência e os impactos das epidemias decresceram, pois "[...] episódios terríveis, como o da aids e o do ebola, no século XXI as epidemias matam uma proporção muito menor de pessoas do que em qualquer outra época desde a Idade da Pedra" (HARARI, 2020, p. 5).

Com o avanço das pesquisas genéticas e científicas, pesquisadores compartilham informações e conseguiram compreender o mecanismo por trás das epidemias, bem como o modo correto de combatê-las. Assim, na Idade Média, não foi possível descobrir a causa da peste negra, atualmente, os cientistas levaram apenas duas semanas para identificar o novo coronavírus, sequenciar seu genoma e desenvolver um teste confiável para detectar pessoas infectadas. Desta forma, entendido como são causadas as epidemias, se torna mais viável combate-las, quer seja por meio de vacinas, antibióticos ou hábitos de higiene aprimorados (HARARI, 2020).

Entrementes, a pandemia que nos assola diferencia-se de todas as outras tragédias do gênero que já acometeram a sociedade, ela possui um caráter global, pois está afetando de forma avassaladora as pessoas em praticamente todos os países do mundo, muito rapidamente e de forma significativa - tanto as relações sociais como o mercado econômico global. Na análise de Santos (2020), de uma maneira cruel, a pandemia mostra como o capitalismo neoliberal incapacitou o Estado para responder as situações emergenciais, como a vivenciada atualmente. Tais respostas que os Estados oferecem à crise variam de Estado para Estado, mas nenhuma destas respostas sobrelevam a incapacidade, bem como sua falta de previsibilidade em relação as emergências. 
Está se vivendo um verdadeiro caos, pois segundo os dados disponibilizados pela Organização Mundial da Saúde (2020), globalmente, até agosto de 2020, houve 19.187.943 casos confirmados de Covid-19, incluindo 716.075 mortes, as quais foram notificadas à OMS. Já o Brasil, segundo a Organização Panamericana de Saúde - OPAS, com base nos dados obtidos a partir de informações das Secretarias Estaduais de Saúde, atingiu na data de 08/08/2020 o total de óbitos registrados de 100.240 de Covid-19, sendo que conta ainda com 2.988.796 casos de Covid-19 notificados. Fica evidente que esta é uma tragédia sem precedentes. Assim sendo, mostra-se extremamente necessário e plausível tecer algumas reflexões, especialmente sobre o momento atual, qual seja, a pandemia do Covid19.

\section{A PANDEMIA DO COVID-19: UM INIMIGO SEM PRECEDENTES}

Vive-se atualmente na era da informação, por isso, os fatos e acontecimentos, influenciados pelos meios de comunicação, das mídias e redes sociais, se espalham rapidamente em todo o mundo, numa escala nunca antes vista, o que por vezes acaba trazendo medo e pânico nas pessoas. Além dos fatos e notícias, esta nova doença também se alastrou de forma avassaladora, por todo o mundo, evidenciando o quanto as pessoas continuam vulneráveis, pois apesar dos avanços tecnológicos e científicos do nosso tempo, a falta de saúde afeta toda a ordem mundial, social e econômica.

O surgimento e propagação de um vírus, denominado, segundo Wu et al. (2020) de Covid-19, doença do coronavírus-19 ou patógeno SARS-CoV-2, está produzindo consequências substanciais e grandes repercussões de ordem social e econômica em muitos países do mundo. Tal fato fez com que a Organização Mundial da Saúde 
caracterizasse a doença como uma pandemia, com a finalidade de orientar os países a envolver os governos e toda a sociedade, por meio de uma estratégia integral e combinada para prevenir as infecções decorrentes do coronavírus, salvar vidas e minimizar os impactos (OPAS/OMS, 2020).

Como já destacado, não é uma "prerrogativa" de nosso tempo o enfrentamento de crises de epidemias, pestes e outras catástrofes. Os coronavírus parecem emergir periodicamente em humanos, principalmente devido à alta prevalência e vasta distribuição de coronavírus, à ampla diversidade genética e à frequente recombinação de seus genomas, e ao aumento das atividades de interface humanoanimal. Animais selvagens e morcegos são considerados como os hospedeiros reservatórios naturais e desempenham um papel crucial na transmissão de vários vírus, incluindo Ebola, Nipah, Coronavírus e outros (WU, et al. 2020, p. 1-3).

O Covid-19 teria surgido na China, onde, segundo WU et al. 2020, p. 2, desde dezembro de 2019 múltiplos casos de pneumonia inexplicáveis foram sucessivamente relatados em alguns hospitais, com histórico de exposição ao grande mercado de frutos do mar na cidade de Wuhan, na província de Hubei, China, confirmando-se ser uma infecção respiratória aguda causada por um novo coronavírus.

Os sintomas do Covid-19 são inespecíficos, sendo que afeta as pessoas e subgrupos potencialmente vulneráveis da população, assim como os idosos e indivíduos com condições crônicas de saúde. A apresentação da doença pode variar desde ausência de sintomas (assintomáticos) à pneumonia severa e morte, não há vacina ou tratamento antiviral para o coronavírus humano e animal. Neste sentido é essencial implementar práticas de controle de infecções por controle de fontes, bloqueio de rotas de transmissão e proteção da população suscetível (WU, et al. 2020).

[...] a primeira coisa que devemos aceitar é que a ameaça está aqui para ficar. Mesmo que esta onda recue, ela reaparecerá em formas novas, talvez até mais perigosas. Por esta razão, podemos esperar que as epidemias virais afetem as nossas interações mais básicas com pessoas e 
objetos ao nosso redor, incluindo o nosso próprio corpo: evitar tocar em coisas que possam estar (invisivelmente) contaminadas, não nos apoiarmos em corrimões, não nos sentarmos em banheiros ou bancadas públicas, evitar abraçar ou apertar a mão das pessoas. Talvez até nos tornemos mais cuidadosos com nossos gestos espontâneos: não tocar nosso nariz ou esfregar os olhos (Žižek, 2020, p. 46).

Ante ao surto da doença que se propaga de forma incontrolável, com as medidas restritivas adotadas, todos estão submetidos a um controle social sem precedentes, mas absolutamente convictos de que de alguma forma superar-se-á esta crise, porém quão altos serão os sacrifícios, já que se está perdendo ou abrindo mão de garantias básicas, de direitos fundamentais arduamente conseguidos em muitos momentos históricos. Porém, "não só somos controlados pelo Estado ou outras instituições similares, como também devemos aprender a controlar e disciplinar-nos a nós mesmos. Talvez só a realidade virtual seja considerada segura e só será permitido mover-se livremente nas ilhas pertencentes aos bilionários" (Žižek, 2020, p. 46).

$\mathrm{O}$ atual modelo globalizado também traz implicações nas relações sociais e no surgimento de novas demandas, se faz necessário uma ressignificação do Estado, das políticas públicas e do direito, com o objetivo de atender as reivindicações da sociedade. A humanidade não pode estar ao arbítrio de um mercado desprovido de qualquer princípio moral, baseado no lucro a qualquer custo, sem preocupação com os direitos humanos e com a dignidade da pessoa humana, principalmente dos segmentos das populações mais pauperizados (SIPPERT, 2017).

A sociedade é marcada pelo consumismo, por uma cultura que valoriza o ter, a qual Baumann (2000, p. 90) define com sendo aquela que "[...] é orientada pela sedução, por desejos sempre crescentes e quereres voláteis - não mais por regularização normativa. [...] se baseia na comparação universal - e o céu é o limite. [...]”. Porém, esta forma de vida traz consequências da exploração predatória sem a preocupação com o meio ambiente, na qual a sociedade é feita refém e que o mercado exige cada vez mais, sendo que isso corrobora com a ausência completa de "[...] sustentabilidade de nosso modo de 
produção, distribuição e consumo de bens e serviços. Não são poucos os analistas do estado da Terra que advertem: "ou mudamos de padrão de relacionamento com a Terra ou vamos ao encontro do pior" (BOFF, 2003, p. 43).

Assim, chega-se num ponto de inflexão, no qual padrões adotados precisam ser ressignificados, ou coloca-se em risco a vida das pessoas e o futuro do planeta. A crise no mercado mundial será inevitável devido à globalização e todas as suas nuances, terá sérias consequências na economia, atingindo principalmente a classe mais pobre, que já sofre com o atual modelo de mercado, porém, com certeza o sistema capitalista irá se reinventar, sendo que cada vida perdida para o coronavírus, as quais não estão podendo nem serem choradas, não poderão jamais serem recuperadas.

Quando um país é atacado por uma determinada epidemia, deve estar disposto a compartilhar honestamente as informações sobre o surto, sem medo de uma catástrofe econômica, ao passo que os outros países devem ser capazes de confiar naquela informação, dispondo-se a estender uma mão amiga em vez de deixar a vítima no ostracismo (HARARI, 2020, p. 7).

Diante disso, observa-se uma dicotomia na atuação do Estado, que se dá entre salvar vidas ou socorrer o mercado. Porém, quando esta escolha for realizada sob o viés econômico, traz também, inevitavelmente, consequências trágicas principalmente para as populações mais vulneráveis. Neste contexto social e político, se faz imperioso ter um diálogo fraterno, pois o direito fundamentado na fraternidade como sendo um direito proposto por todos e para todos desvela-se em um grande mecanismo de promoção e efetivação dos direitos humanos e, em especial neste momento, da saúde como um direito. 


\section{A SAÚdE NO CENÁRIO DA PANDEMIA: UMA NECESSÁRIA QUEBRA DE PARADIGMAS}

A propagação do Covid-19 potencializou os problemas, em um período multifacetado e complexo, pelo qual a humanidade atravessa. A pandemia do coronavírus está mudando e vai mudar ainda mais a vida de todos. Isso nos obriga a repensar a política e a economia e a refletir sobre o nosso presente, o nosso passado e o nosso futuro (FERRAJOLI, 2020, p. 8). Tal situação, também está e continuará fazendo ingerência no sistema do direito e também no sistema de saúde.

Deste modo, é oportuno repensar o contexto no qual está inserido o direito à saúde junto à sociedade, por meio da metateoria do Direito Fraterno. A fraternidade supera o egoísmo vigente na sociedade cosmopolita, possibilitando uma transformação social, construindo uma sociedade fundada na igualdade e na dignidade (STURZA; MARTINI, 2019). Uma das metas do Direito Fraterno, é "fazer refletir sobre a responsabilidade de cada um que compartilha o caráter de humanidade" (GIMENEZ; FINK, 2019, p. 217). Pois,

\footnotetext{
O direito à saúde, sob a perspectiva da metateoria do Direito Fraterno, deve ser pensado como acesso aos serviços de saúde e bem comum de toda a humanidade, haja vista que a fraternidade vai ao encontro do bom e harmônico convívio com os outros; é um direito que é para todos e aceito e/ ou proposto por todos (GIMENEZ; FINK, 2019, p. 217).
}

Assim, para enfrentar as consequências da pandemia, não bastam apenas regras e sanções, é necessário que seja compartilhado por todos a plena consciência que se faz necessário para proteger a sua saúde e a sua vida e a dos outros (FERRAJOLI, 2020). Saúde é "um dos principais componentes da vida, seja como pressuposto indispensável para sua existência, seja como elemento agregado à sua qualidade. Assim, a saúde se conecta ao direito à vida" (SCHWARTZ, 
2001, p. 52). Na doutrina de Sousa (2015), o direito à vida é o mais fundamental e importante de todos os direitos, pois a partir da vida e uma vida saudável, é que se pode exigir a efetivação de todos os direitos fundamentais.

O conceito de saúde como um marco referencial está no preâmbulo da Constituição da Organização Mundial de Saúde (OMS), que é uma agência especializada da Organização das Nações Unidas (ONU) voltada para a saúde, a qual dispõe que "A saúde é um estado de completo bem-estar físico, mental e social, e não consiste apenas na ausência de doença ou de enfermidade" (OMS/WHO, 1946). Destacase que para ter acesso à saúde e uma boa e eficaz consecução dos serviços sanitários é necessária uma cooperação entre os indivíduos e os Estados, como bem prevê a Constituição da Organização Mundial da Saúde, pois, somente com o gozo do melhor estado de saúde é que se torna possível atingir os direitos fundamentais de todo o ser humano, sem distinção de raça, de religião, de credo político, de condição econômica ou social.

$\mathrm{O}$ direito à saúde também se encontra positivado em outro importante documento, a Declaração Universal dos Direitos Humanos (DUDH), a qual é um marco significativo na história dos direitos humanos, pois foi elaborada com o intuito de estabelecer a proteção universal a estes direitos. É no seu artigo XXV, 1, que a Declaração Universal dos Direitos do Homem faz referência ao direito à saúde $\mathrm{e}$ bem-estar, determinando que:

Todo ser humano tem direito a um padrão de vida capaz de assegurar-lhe, e a sua família, saúde e bem-estar, inclusive alimentação, vestuário, habitação, cuidados médicos e os serviços sociais indispensáveis, e direito à segurança em caso de desemprego, doença, invalidez, viuvez, velhice ou outros casos de perda dos meios de subsistência em circunstâncias fora de seu controle.

No Brasil, a Carta Magna de 1988 seguiu a concepção do Estado de bem-estar social, trazendo o Estado como o grande provedor de direitos básicos, como por exemplo saúde e educação. Portanto, o direito à saúde, no ordenamento jurídico brasileiro, tem embasamento 
de ordem constitucional, como um direito de todos e dever do Estado, a quem cabe a obrigação de garantir a melhor prestação sanitária, por meio de políticas públicas adequadas e eficientes. Preceitua o art. 194 da Constituição Federal que é de responsabilidade do Estado, juntamente com toda a sociedade, assegurar a saúde da população. Este marco regulatório mostra-se de fundamental importância, principalmente neste momento, pois "Ao infectar indistintamente, qualquer pessoa, o coronavírus expôs o valor inestimável da saúde pública e a necessidade de seu caráter universalista e gratuito" (FERRAJOLI, 2020, p. 9).

Para que o Estado possa atingir o objetivo de permitir o direito à saúde, existem muitos óbices a serem superados, alguns dos quais são construções históricas, que necessitam de uma ressignificação da sociedade. Existem outros empecilhos, porém, que são imposições do modelo econômico vigente, que privilegia a capitalização em detrimento de atender de forma satisfatória e que também impedem a consecução de tais objetivos, e, em relação a saúde, com preferência ao sistema privado, voltado essencialmente para o lucro em detrimento da saúde pública (FERRAJOLI, 2020). Neste sentido,

Inobstante o alto grau de relevância constitucional outorgado, pela Constituição Federal, ao direito à saúde, no Brasil, sua efetivação ainda continua insuficiente. Destarte, constatou-se que remanescer à espera de mudanças legislativas e, sobretudo, de medidas administrativas eficientes, colocaria em risco, ante a demora, a integridade física daqueles que necessitam de assistência médico-hospitalar ou de medicamentos específicos (SILVA e PESSOA, 2017, p. 16).

Assim, são várias questões que impedem a efetivação do direito fundamental e suas implicações na consecução do direito à saúde, pois o modelo econômico brasileiro traz como consequência uma grande concentração de renda e falta de infraestrutura básica. Com a exclusão de alguns segmentos sociais de um nível de qualidade de vida satisfatório, os quais sofrem com problemas de saúde, em virtude das precárias condições sanitárias e ambientais a que estão submetidos, as quais são propiciadoras de doenças, levam a uma sobrecarga do setor 
de saúde com pacientes acometidos de doenças que poderiam na grande maioria dos casos, serem evitadas (RIBEIRO, 2004).

Desta forma, além da falta do acesso à saúde ou a sua disponibilização precária, que por si só já seria suficiente para não permitir ao cidadão a sua dignidade, a pandemia do coronavírus veio a agravar as terríveis condições a que as populações de mais baixa renda estão expostas. Essa situação se intensifica com a falta de outras prestações sociais fundamentais, tais como falta de alimentação e de nutrição adequada, que possibilite uma vida saudável e um sistema imunológico com baixa ou nenhuma incidência de doenças.

Além disso, há também a falta de habitação e saneamento básico, para evitar a proliferação de doenças e também dos agentes causadores, bem como a uma higienização adequada. Assim, nesta sociedade marcada pela desigualdade social, há um contrassenso entre aquelas pessoas que tem que ficar em casa na "quarentena", em situação de isolamento social, sem nem ao menos ter as mínimas condições nas residências onde moram em detrimento a quem tem boa situação econômica e social. Sendo que,

[...] estas medidas sejam estabelecidas por normas gerais e abstratas, aumentam e dramatizam as desigualdades: entre os que podem ficar em casa e os que são obrigados a ir trabalhar, entre os que têm casa e os que não têm, entre os que têm grandes casas com jardins ou terraços e os que são obrigados a viver num quarto, entre os que estão sós e entre os pobres e os que vivem com as suas famílias (FERRAJOLI, 2020, p. 9).

O Covid-19 pode alcançar a todos, sua forma invisível de se propagar não escolhe classe social, condição econômica ou qualquer outro tipo de estratificação. "De repente a epidemia do coronavírus, com a sua carga diária de mortos e infectados, colocou os cuidados de saúde no centro das preocupações de todos" (FERRAJOLI, 2020, p. 9). Porém, as piores consequências ou as dificuldades de acesso a um tratamento adequado sempre afetam os mais pobres e também aquelas pessoas vulneráveis. As consequências sobre à saúde, "distribuem-se de maneira diferente segundo os indivíduos, regiões e 
grupos sociais e relacionam-se com a pobreza, com o modelo de produção e reprodução social, cultura e organização territorial, e com o nível educacional" (VILLARDI, 2015, p. 22).

Assim, deve(riam) ser (re)consideradas a racionalidade das decisões, como uma nova forma de enfrentar os problemas da sociedade, baseado na valorização da vida humana. Sendo assim, necessário seria que a Organização Mundial da Saúde fosse uma verdadeira instituição de garantia global, com poderes principalmente para dispor de meios econômicos necessários para enfrentar a crise com medidas racionais e adequadas, as quais não poderiam ficar condicionadas por interesses políticos ou econômicos contingentes em cada país, mas sim, propiciar a garantia da vida de todos os seres humanos simplesmente por serem humanos (FERRAJOLI, 2020).

Denota-se que a OMS atua de forma deliberativa nas suas orientações, sendo que cada país adota uma medida, ou deixa de adotar as medidas, muitas vezes influenciados por discussões ideológicas partidárias ultrapassadas e que não tem ou não deveriam ter o menor sentido, diante de toda a crise instalada. Para Ferrajoli (2020), a partir dessa tragédia do coronavírus, é possível que possa nascer uma consciência geral que leve em consideração o nosso destino comum, baseada em um sistema comum de garantia dos nossos direitos e da nossa convivência, a qual deve ser sempre pacífica e solidária.

A crise sem precedentes causada pela pandemia do coronavírus, que afeta os mercados econômicos mundiais, os Governos e os indivíduos, principalmente os mais pobres e os grupos de risco, faz repensar o modelo e os valores da sociedade, bem como faz refletir a "[...] a falta de instituições de garantias globais adequadas, que deveriam ter sido introduzidas para instituir as muitas cartas internacionais dos direitos humanos" (FERRAJOLI, 2020, não paginado).

Quais serão as consequências da pandemia, que tipo de pessoas nos tornaremos, ou como vai ser o mundo, como serão as relações das pessoas umas com as outras, bem como o sistema econômico, após o 
Covid-19? Dentre os muitos efeitos que podem advir desta crise sem precedentes, certamente haverá "depois de anos de ódio, de racismo e de sectarismos - de um senso extraordinário e inesperado de solidariedade entre as pessoas e entre os povos" (FERRAJOLI, 2020, não paginado). Com efeito, espera-se que se desenvolva um senso de solidariedade entre as pessoas, pois toda crise também é uma oportunidade. Espera-se que a epidemia atual ajude a humanidade a perceber o grave perigo que representa a desunião global (HARARI, 2020).

Conforme destaca Harari (2020), neste momento de crise, a luta crucial ocorre dentro da própria humanidade. Se essa epidemia resultar em maior desunião e desconfiança entre os seres humanos, será mais difícil combater este inimigo invisível. Porém, se a epidemia resultar em uma cooperação global de todos os países, será uma vitória não apenas contra o coronavírus, mas contra todos os patógenos futuros. Assim, percebe-se que a "Xenofobia, isolacionismo e desconfiança agora caracterizam a maior parte do sistema internacional. Sem confiança e solidariedade global, não seremos capazes de parar a epidemia de coronavírus, e provavelmente veremos mais dessas epidemias no futuro" (HARARI, 2020, não paginado).

Impende neste momento, ante toda a angústia, a necessidade de ressignificação da sociedade, trazer a baila a metateoria do direito fraterno como sendo um pacto entre iguais, de identidade comum, numa sociedade que busca a concretização do direito como uma forma de respeito e reconhecimento. Pois,

[...] a fraternidade apresenta-se como um caminho para a consolidação dos direitos fundamentais, pois o resgate deste pressuposto iluminista, ao mesmo tempo em que traz novos desafios, recupera a velha ideia de ver o outro como um outro EU; mais do que isso, a fraternidade está fundada na lei da amizade, no compartilhar, no pactuar (STURZA; MARTINI, 2019, p. 41).

Resta (2004), aduz que o direito fraterno é direito jurado em conjunto, num olhar voltado ao futuro, onde homens e mulheres fazem um pacto no qual se "decide compartilhar" regras mínimas de 
sobrevivência, livre da tirania e da inimizade. Assim tem-se que a possibilidade da fraternidade e da solidariedade mostram-se como uma importante alternativa na análise das consequências da saúde das pessoas em época de pandemia, pois é "uma aposta no processo de transformação social. Neste processo, o direito à saúde é um tema que ultrapassa as fronteiras de todos os tipos, pois a ideia do outro como irmão não suporta delimitações territoriais, nem outras delimitações” (STURZA; MARTINI, 2019, p. 40).

A aposta no pressuposto da fraternidade acontece porquê, através dele, é possível superar a inimizade e as diversas formas de guerra que se mascaram na sociedade global. Assim, a fraternidade retorna com força diante da crise do Estado-nação e da necessidade de solidificar uma sociedade cosmopolita, na qual a humanidade é ameaçada somente pela própria humanidade (STURZA; MARTINI, 2019, p. 45).

Assim, ter e dispor de saúde são condições essenciais para uma boa qualidade de vida. Sem estas, torna-se improvável que o indivíduo tenha uma vida digna e possa exercer a sua cidadania de forma plena, com condições de efetivar a (re)construção dos direitos humanos numa sociedade cada vez mais globalizada e sectária. Desta forma, a relação do direito à saúde com o conceito de fraternidade ressignifica “o egoísmo vigente nesta sociedade cosmopolita, na qual a possibilidade de transformação social é concreta, assim como são concretos os desafios para a construção de uma sociedade fundada no respeito ao outro como um outro EU” (STURZA; MARTINI, 2019, p. 77).

Segundo Jaborandy (2016, p. 57), “a fraternidade propõe-se a restaurar a esfera ética na vida pública e conscientizar os indivíduos da responsabilidade que possuem pelos outros e, consequentemente, pelo bem da comunidade”, principalmente neste momento, como forma de garantia e alternativa eficaz para a e efetivação do direito à saúde.

Nesse sentido, a proteção e o acesso ao direito à saúde são pressupostos para que o ser humano (eu e o outro) possa/mos ter uma vida digna. A efetivação dos direitos humanos e fundamentais reivindica uma transformação social no sentindo de que as pessoas 
possam viver sem sofrer discriminação ou qualquer tipo de violência, com respeito ao outro, tolerância e aceitando a suas diferenças. Tal pressuposto é necessário para que todos possam viver de forma livre e plena, bem como coexistir de forma pacífica e harmoniosa.

\begin{abstract}
A fraternidade reconstrói, desse modo, o sentido universal da experiência humana nas relações políticas e sociais uma vez que "remete à ideia de um "outro" que não sou eu nem minha esfera social, mas o "diferente" diante do qual tenho deveres e responsabilidades, e não somente direitos a opor". Ao postular o reconhecimento do outro, o enraizamento do indivíduo na comunidade, a responsabilidade individual e estatal, o princípio da fraternidade completa a teoria dos direitos fundamentais, em face da suplantação de construções identitárias de forte raiz liberal para a realização da alteridade (JABORANDY, 2016, p. 66).
\end{abstract}

Assim sendo, o direito à saúde necessita ultrapassar todos os tipos de fronteiras e obstáculos, sendo que as pessoas que diretamente ou indiretamente estão sendo afetadas pela pandemia do Covid-19 precisam ser vistas como sendo parte do EU, pois a ideia do outro como irmão não suporta delimitações territoriais, nem outras delimitações, se coadunando com os princípios do direito fraterno.

A metateoria do direito fraterno pressupõe o desvelamento de paradoxos, que levam a questionamentos, de qual a função da fraternidade na sociedade cosmopolita, que é fundamental para entender o que significa o direito fraterno, suas possibilidades e suas limitações na efetivação dos direitos humanos, necessitando-se, por vezes, de uma ruptura de paradigmas de certos modelos existentes, pois principalmente no Brasil verifica-se que as atrocidades em função de direitos fundamentais ocorreram e ocorrem ainda de forma sistemática.

Para Resta apud Sturza e Martini (2019), a fraternidade referida na revolução iluminista continua inédita e não resolvida em relação à igualdade e à liberdade, e retorna agora vinculada à ideia de globalização e à necessária ruptura de fronteiras, na qual a condição de dependência de tudo e de todos é cada dia mais evidente. Resta (2004) afirma que o direito fraterno trata de um "modelo de direito que abandona o confim fechado da cidadania e olha para a forma nova 
de cosmopolitismo que não são os mercados, mas a obrigatoriedade universalista de respeitar os direitos humanos" (RESTA, 2004, p. 135).

Justamente por isso torna-se imprescindível a análise da atual conjuntura e seus impactos na saúde das pessoas, no viés do direito fraterno. Entretanto, eles só fazem sentido em uma sociedade que tenha a percepção de que somos um único povo, que a pandemia está afetando todo o gênero humano, sem distinção de nacionalidade e riqueza, com a plena consciência da nossa interdependência, da nossa fragilidade, bem como do nosso destino comum (FERRAJOLI, 2020).

\section{CONSIDERAÇÕES FINAIS}

A disseminação da pandemia do vírus Covid-19 mostra o quanto as pessoas e a própria sociedade continuam vulneráveis, pois apesar dos avanços tecnológicos e científicos do nosso tempo, a falta de saúde está afetando toda a ordem mundial, social e econômica, atingindo todos os segmentos da humanidade, porém de forma implacável aos mais pobres e desassistidos.

O novo coronavírus é um inimigo invisível e silencioso, sendo que ainda não existe o desenvolvimento de uma vacina e nem a descoberta de medicamentos que sejam eficientes no tratamento da doença, em que pese todo o esforço da ciência neste sentido. Porém algumas medidas são estritamente necessárias de serem adotadas, sendo que uma das principais medidas é o isolamento social das pessoas, uma medida restritiva que pode vir afetar demasiadamente a ordem econômica.

Ocorre que o Covid-19 está causando milhares de mortes, produzindo consequências substanciais e grandes repercussões de ordem social e econômica em praticamente todos os países do mundo, principalmente nas populações que historicamente já sofrem, evidenciando que está prestes a ocorrer uma tragédia sem precedentes 
se medidas corretas não forem adotadas principalmente pelos governos.

As dúvidas e angústias são recorrentes neste momento, já que existe a possibilidade de isolar-se e evitar a propagação do vírus salvando vidas, mas em contrapartida tem-se o mercado financeiro que também está pedindo socorro. A saúde, mais do que nunca, é uma preocupação de todos, remetendo constantemente ao pensamento (e dúvida!) sobre quem viverá e quem morrerá durante esta pandemia. $\mathrm{E}$ por fim, resta ainda uma grande preocupação acerca das garantias e direitos fundamentais, que são construções históricas e indisponíveis, essenciais a vida de todos. Estas e tantas outras preocupações fazemse presentes diuturnamente nesta situação pandêmica, reforçando a importância de repensar o modelo anacrônico de sociedade, bem como o momento disruptivo que virá após o Covid-19.

De acordo com a história da humanidade, sempre houveram epidemias e doenças contagiosas, que se espalharam causando muitos danos para a humanidade, porém, sempre marcaram rupturas significativas na sociedade, sendo que também foram oportunidade para a sociedade poder se reinventar e se ressignificar.

A ruptura de paradigmas e a ressignificação de valores serão significativas e inevitáveis na sociedade atual, necessitando, a sociedade, o direito e a saúde, serem repensadas. Nesse contexto, surge a necessidade premente de um direito que inclui, fundado num pacto entre irmãos, assim sendo, desvela-se de forma insofismável o estudo da metateoria do direito fraterno, sobretudo repensando o direito à saúde.

Assim, na perspectiva da metateoria do direito fraterno, como sendo um pacto entre iguais, de identidade comum, que busca a concretização do direito como uma forma de respeito e reconhecimento, de forma universal, faz-se necessário repensar a sociedade e o direito à saúde - os quais estão sendo implacavelmente assolados pela pandemia do Covid-19, como possibilidade de ressignificação da dogmática jurídica e social posta, visando sempre a 
união de ideias e de ações, que se perfectibilizam em um bem viver em comunidade.

Data de Submissão: 26/07/2020

Data de Aprovação: 10/08/2020

Processo de Avaliação: double blind peer review

Editor Geral: Jailton Macena de Araújo

Editor de Área: Jailton Macena de Araújo

Assistente Editorial: Bruna Agra de Medeiros

\section{REFERÊNCIAS}

BAUMANN, Zygmunt. Modernidade Líquida. Tradução Plínio Dentzien. Rio de Janeiro: Jorge Zahar Editor, 2000.

BEDIN, Gilmar Antonio. Os direitos do homem e o neoliberalismo. 3. ed. Ijuí: Unijuí, 2002.

BOBBIO, Norberto. A Era dos Direitos. Tradução Carlos Nelson Coutinho. Rio de Janeiro. Editora Campus. 1992.

BOFF, Leonardo. Ecologia e Espiritualidade. In: TRIGUEIRO. André. (Org.). Meio Ambiente do Século 21. Rio de Janeiro: Sextante, 2003.

BRASIL. Constituição (1988). Constituição da República Federativa do Brasil. Disponível em:

<http://www.planalto.gov.br/ccivil_03/Constituicao/Constituicao.ht m>. Acesso em: 13 abr. 20.

CURY, Ieda Tatiana. Direito fundamental à saúde: Evolução, Normatização e Efetividade. Rio de Janeiro, Lumenjuris, 2005.

DALLARI, Sueli Gandolfi. A saúde do brasileiro. São Paulo Paulo: Editora Moderna, 1987

DUDH. Declaração Universal dos Direitos do Homem (1948). Disponível em: $<$ http://www.ghente.org/doc_juridicos/decdirhumanos.htm>. Acesso em: 11 abr. 2020 
A Pandemia Covid-19 Como Um Inimigo Invisível E Silencioso: 0 Direito À Saúde...

FERRAJOLI, Luigi. O que nos ensina o Coronavírus? Revista Direitos Humanos e Democracia, Editora Unijuí, Ano 8, n. 15, p. 7-11, Jan./Jun. 2020. Traduzido por: Doglas Cesar Lucas. Disponível em: <http://dx.doi.org/10.21527/2317-5389.2020.15.7-11>. Acesso em: 28 jun. 2020.

FERRAJOLI, Luigi. O vírus põe a globalização de joelhos. 2020. Disponível em: <http://www.ihu.unisinos.br/597204-o-viruspoe-a-globalizacao-de-joelhos-artigo-de-luigi-ferrajoli > . Acesso em: $11 \mathrm{abr} .2020$.

FERRAJOLI, Luigi. Por uma teoria dos direitos e dos bens fundamentais. Porto Alegre: Livraria do Advogado Editoria. 2011.

GIMENEZ, Charlise Paula Colet; FINK, Lígia Daiane. O direito humano fundamental à saúde no Brasil na perspectiva do direito fraterno. In: MARTINI, Sandra Regina; STURZA, Janaína Machado; FINCO, Matteo. Direito à Saúde: Ponte para a Cidadania - O MOVIMENTO ENTRE OS SABERES - A transdisciplinaridade e o direito: Volume XII. 1. ed. Porto Alegre / RS: Evangraf, 2019. v. XI. 120p

HARARI, Yuval Noah. A crise do Coronavírus. 2020. Disponível em: <https://www.hsm.com.br/o-que-yuval-noah-harari-pensasobre-o-coronavirus/> . Acesso em: 11 abr. 2020.

HARARI, Yuval Noah. Na batalha contra o coronavírus, faltam líderes à humanidade. Tradução: Odorico Leal. Editora:

Companhia das Letras. 2020. E-Book. Disponível em:

$<$ Yuval_Noah_Harari_Na_batalha_contra_o_coronavírus?id=vVbZ DwAAQBAJ>. Acesso em: 28 jun. 2020.

JABORANDY, Clara Cardoso Machado. A fraternidade no Direito Constitucional Brasileiro: um instrumento para a proteção de direitos fundamentais transindividuais. 2016. Repositório da Universidade Federal da Bahia. Disponível em: < https://repositorio.ufba.br/ri/bitstream/ri/20048/1/CLARA\%20CARDOSO\%20MACHADO\%2OJABORANDY.pdf >. Acesso em: $10 \mathrm{abr} .2020$.

MELO, Osvaldo Ferreira de. Dicionário de Direito Político. Rio de Janeiro: Forense, 1978

ORGANIZAÇÃO MUNDIAL DE SAÚDE (OMS). Constituição da Organização Mundial da Saúde (OMS/WHO) - 1946. Disponível em: <www.direitoshumanos.usp.br/index.php/OMSOrganização-Mundial-da-Saúde/constituicao-da-organizacaomundial-da-saude-omswho.html> Acesso em: 11 abr. 2020. 
ORGANIZAÇÃO MUNDIAL DE SAÚDE (OMS). Painel da Doença de Coronavírus da OMS (COVID-19). Disponível em: <https://covid19.who.int/> Acesso em: 08 ago. 2020.

ORGANIZAÇÃO PAN-AMERICACANA DA SAÚDE NO BRASIL OPAS. Informações. Disponível em: $<$ https://www.paho.org/bra/?gclid=EAIaIQobChMIgpvx9M6Q6 wIVCQeRCh1ZegLgEAAYASAAEgK1GfD BwE> Acesso em: 08 ago. 2020.

ORGANIZAÇÃO PANAMERICACANA DA SAÚDE NO BRASIL OPAS. OMS afirma que COVID-19 é agora caracterizada como pandemia. Disponível em:

<https://www.paho.org/bra/index.php?option=com_content\&view= article\&id=6120:oms-afirma-que-covid-19-e-agora-caracterizadacomo-pandemia\&Itemid=812> Acesso em: 08 ago. 2020.

RESTA, Eligio. O Direito Fraterno. Trad. Sandra Regina Martini Vial (coordenação). Santa Cruz do Sul: EDUNISC, 2004.

RIBEIRO, Helena. Saúde Pública e meio ambiente: evolução do conhecimento e da prática, alguns aspectos éticos. Saúde e Sociedade, São Paulo, v. 13, n. 1, p. 70-80, abr. 2004. Disponível em: <http://dx.doi.org/10.1590/So104-12902004000100008>. Acesso em: 11 abr. 2020.

ROBERTS, John M. O livro de ouro da história do mundo. Tradução Laura Alves e Aurélio Rebello. Rio de Janeiro: Ediouro, 2001.

SANTOS, Boa Ventura de Sousa. A cruel pedagogia do vírus. Editora Almedina. 2020.

SCHWARTZ, Germano. Direito à saúde: efetivação de uma perspectiva sistêmica. Porto Alegre: Livraria do Advogado Editora, 2001.

SCHWARTZ, Germano. O tratamento jurídico do risco no direito à saúde. Porto Alegre: Livraria do Advogado Editora, 2004.

SILVA, De Plácido e. Vocabulário jurídico. Edição Universitária. Volume I. 2. ed. Rio de Janeiro: Forense, 1990.

SILVA, Orlando Sampaio; PESSOA, Flávia Moreira Guimarães. A efetivação democrática do direito à saúde mediante a tutela coletiva e o incidente de coletivização de demandas individuais. Prima Facie, v. 16, n. 32, p. 01-45, 2017. Disponível em: <

https://periodicos.ufpb.br/index.php/primafacie/article/view/34192 >. Acesso em: Acesso em: 08 ago. 2020.

SIPPERT. Evandro Luis. O Direito Fundamental à Saúde: a (in)sustentabilidade e a função do Estado garantidor em 
A Pandemia Covid-19 Como Um Inimigo Invisível E Silencioso: 0 Direito À Saúde...

face das demandas sanitárias. Dissertação (Dissertação em Direito). Unijuí. Ijui. p. 143. 2017. Disponível em:

<http://bibliodigital.unijui.edu.br:808o/xmlui/handle/123456789/6 288>. Acesso em: 08 ago. 2020.

SOUSA, Simone Letícia Severo e. Direito à saúde e políticas públicas: do ressarcimento entre os gestores públicos e privados da saúde. Belo Horizonte: Del Rey, 2015.

STURZA, Janaína Machado; MARTINI, Sandra Regina. Direitos Humanos: saúde e fraternidade - O MOVIMENTO ENTRE OS SABERES - A transdisciplinaridade e o direito: Volume XI. 1. ed. Porto Alegre / RS: Evangraf, 2019. v. XI. 120p

STURZA, Janaína Machado; MARTINI, Sandra Regina. Direitos. A produção do direito através de um espaço de todos e para todos: o direito à saúde da população migrante, In: STURZA, Janaína Machado; MARTINI, Sandra Regina (Org). Direitos Humanos: saúde e fraternidade - O MOVIMENTO ENTRE OS SABERES - A transdisciplinaridade e o direito: Volume XI. 1. ed. Porto Alegre / RS: Evangraf, 2019. v. XI. 120p.

STURZA, Janaína Machado; MARTINI, Sandra Regina. Direitos. O direito humano à saúde na sociedade cosmopolita: a saúde como bem da comunidade e ponte para a cidadania. In: STURZA, Janaína Machado; MARTINI, Sandra Regina (Org). Direitos Humanos: saúde e fraternidade - O MOVIMENTO ENTRE OS SABERES - A transdisciplinaridade e o direito: Volume XI. 1. ed. Porto Alegre / RS: Evangraf, 2019. v. XI. 120p

VILLARDI, Juliana Wotzasek Rulli. A vigilância em saúde ambiental no Brasil - uma reflexão sobre seu modelo de atuação: necessidades e perspectivas. 2015. $108 \mathrm{f}$. Tese (Doutorado em Ciências) - Escola Nacional de Saúde Pública Sérgio Arouca, Fundação Osvaldo Cruz, Rio de Janeiro, 2015.

WU, Di; WU, Tiantian; LIU, Qun; YANG, Zhicong; et al. The SARSCoV-2 outbreak: what we know. International Journal of Infectious Diseases. Published online March 12, 2020. Traduzido por: Flávia Renata Ropelatto Pires e Sofia Mitsue Ishie. Disponível em: <http://www.toledo.ufpr.br/portal/wpcontent/uploads/2020/03/O-surto-da-SARS-CoV-2-o-queno\%CC\%81s-sabemos.pdf.pdf> Acesso em: 11 abr. 2020.

ŽIŽEK, Slavoj. Um golpe como "KILL BILL" no capitalismo. In: DAVIS, Mike, et al: Coronavírus e a luta de classes. Terra sem Amos: Brasil, 2020. 


\title{
Pandemic Covid-19 As An Invisible And Quiet Enemy: The Right To Health In Times Of Survival
}

\author{
Janaína Machado Sturza
}

\section{Evandro Luís Sippert}

\begin{abstract}
The right to health is related to an essential guarantee for the full development and satisfaction of people's quality of life, because at the center of everything must be respect for man, for his dignity and for his inalienable rights, essential to his survival in a world in which risks are globalized, invisible and silent. In this sense, the study now proposed aims to analyze the implications of the spread of the Covid-19 virus pandemic on the right to health, in a context of global crisis in terms of health and humanitarian. This article constitutes a bibliographic review, based on the deductive method and using, as an alternative of analysis, the metatheory of Fraternal Law. Finally, it was found that this pandemic presented us with the need to break paradigms, starting from the redefinition of society, especially from the perspective of the right to access to health as a way of survival.
\end{abstract}

Keywords: health crisis; right to health; pandemic; survival.

DOI: https://doi.org/10.22478/ufpb.1678-2593.2020v19n42.54163

Conteúdo sob licença Creative Commons: Attribuition-NonCommercial-NoDerivative 4.o International (CC BY-NC-ND 4.0) 